\title{
A novel folate-modified self-microemulsifying drug delivery system of curcumin for colon targeting
}

\author{
This article was published in the following Dove Press journal: \\ International Journal of Nanomedicine \\ 7 January 2012 \\ Number of times this article has been viewed
}

\author{
Lin Zhang ${ }^{*}$ \\ Weiwei Zhu' ${ }^{2 *}$ \\ Chunfen Yang' \\ Hongxia Guo' \\ Aihua Yu' \\ Jianbo $\mathrm{Ji}^{3}$ \\ Yan Gao' \\ Min Sun' \\ Guangxi Zhai' \\ 'Department of Pharmaceutical \\ Engineering, College of Pharmacy, \\ Shandong University, Jinan; \\ ${ }^{2}$ Department of Pharmacy, Yantai \\ Yuhuangding Hospital, Yantai; \\ ${ }^{3}$ Department of Pharmacology, \\ College of Pharmacy, Shandong \\ University, Jinan, China \\ *These authors contributed equally \\ to the work
}

Correspondence: Guangxi Zhai

Department of Pharmaceutics, College of Pharmacy, Shandong University, 44 Wenhua Xilu, Jinan 2500I2, China

Tel +8653188382015

Fax +8653 I 8838273 I

Email professorgxzhai@yahoo.cn
Background: The objective of this study was to prepare, characterize, and evaluate a folate-modified self-microemulsifying drug delivery system (FSMEDDS) with the aim to improve the solubility of curcumin and its delivery to the colon, facilitating endocytosis of FSMEDDS mediated by folate receptors on colon cancer cells.

Methods: Ternary phase diagrams were constructed in order to obtain the most efficient self-emulsification region, and the formulation of curcumin-loaded SMEDDS was optimized by a simplex lattice experiment design. Then, three lipophilic folate derivatives (folatepolyethylene glycol-distearoylphosphatidylethanolamine, folate-polyethylene glycol-cholesteryl hemisuccinate, and folate-polyethylene glycol-cholesterol) used as a surfactant were added to curcumin-loaded SMEDDS formulations. An in situ colon perfusion method in rats was used to optimize the formulation of FSMEDDS. Curcumin-loaded FSMEDDS was then filled into colon-targeted capsules and the in vitro release was investigated. Cytotoxicity studies and cellular uptake studies was used in this research.

Results: The optimal formulation of FSMEDDS obtained with the established in situ colon perfusion method in rats was comprised of $57.5 \%$ Cremophor $^{\circledR}$ EL, 32.5\% Transcutol $^{\circledR}$ HP, $10 \%$ Capryol $^{\mathrm{TM}}$ 90, and a small amount of folate-polyethylene glycol-cholesteryl hemisuccinate (the weight ratio of folate materials to Cremophor EL was 1:100). The in vitro release results indicated that the obtained formulation of curcumin could reach the colon efficiently and release the drug immediately. Cellular uptake studies analyzed with fluorescence microscopy and flow cytometry indicated that the FSMEDDS formulation could efficiently bind with the folate receptors on the surface of positive folate receptors cell lines. In addition, FSMEDDS showed greater cytotoxicity than SMEDDS in the above two cells.

Conclusion: FSMEDDS-filled colon-targeted capsules are a potential carrier for colon delivery of curcumin.

Keywords: curcumin, SMEDDS, folate receptor, colon targeting

\section{Introduction}

Curcumin, a polyphenol of turmeric, is derived from the rhizomes of Curcuma longa, which can suppress the tumorigenic activity of various cancers, such as the colon, duodenum, esophagus, forestomach, stomach, liver, breast, leukemia, oral cavity, and prostate. ${ }^{1,2}$ Five Phase I clinical trials have demonstrated the safety and tolerability of curcumin in colorectal cancer patients. ${ }^{3}$ In spite of this huge potential of curcumin as an effective chemotherapy agent against colon cancer, it has poor systemic availability due to its low aqueous solubility, efficient first-pass effect, and some degree of intestinal metabolism when administered via the oral route. It has been demonstrated that a 
large daily oral dose of $3.6 \mathrm{~g}$ of curcumin resulted in pharmacologically efficacious levels in colorectal tissue. ${ }^{4}$

Current trends of curcumin in the treatment of colon cancer have concentrated on the development of potential delivery systems to increase its aqueous solubility and bioavailability as well as controlled delivery of curcumin at or around cancer tissues. ${ }^{5}$ Recently, much attention has been given to self-microemulsifying drug delivery systems (SMEDDS) to enhance the solubility, dissolution, and oral absorption for poorly water-soluble drugs, such as itraconazole, oridonin, coenzyme Q10, and zedoary essential oil..$^{6-9}$ SMEDDS is an isotropic and thermodynamically stable solution consisting of oil, surfactant, cosurfactant, and drug, which can spontaneously form oil-in-water microemulsion when mixed with water under gentle stirring. The microemulsion presents the drug in a dissolved form, and the small droplet size (less than $100 \mathrm{~nm}$ ) provides a large interfacial surface area favoring drug absorption.

For efficient drug delivery, a carrier system should facilitate not only tumor localization but also intracellular access. Folate receptor is a glycosylphosphatidylinositol-linked membrane glycoprotein of $38 \mathrm{kDa}$, which is overexpressed on the surface of most solid tumors, including colorectal carcinoma. ${ }^{10}$ In recent years, it has been demonstrated that folate receptor-mediated uptake of the vitamin folic acid could be exploited to facilitate entry of an attached liposome or emulsion into cells. ${ }^{11,12}$

In the present study, an attempt was made to improve the solubility and targeted-delivery of curcumin to the colon by formulating it as folate-modified SMEDDS (FSMEDDS) and filling the formulation into colon-targeted capsules coated by Eudragit ${ }^{\circledR}$ S 100 (Evonik Industries AG, Essen Germany), a coating material for colonic delivery because of it will not dissolve under the condition of $\mathrm{pH}<7 .{ }^{5}$ Under conditions of colon fluid, curcumin-loaded SMEDDS (CUR-SMEDDS) containing folate conjugated material can form a microemulsion and then it can bind with folate receptors at the surface of colorectal tissues or colon cancer cells to increase the absorption in the colon or induce the endocytosis of CUR-FSMEDDS. ${ }^{10,13}$

The main objectives of this study were to develop and characterize a CUR-SMEDDS formulation for colon targeting and to evaluate its anticancer effects. An efficient CUR-SMEDDS formulation was developed using solubility and phase diagrams. The formulation optimization of CUR-FSMEDDS was conducted with the established in situ colon perfusion method in rats. The developed formulations were characterized by assessing morphology, particle size, and zeta potential.
Cytotoxicity of SMEDDS and FSMEDDS was evaluated by 3-(4,5-dimethyl-2-thiazolyl)-2,5-diphenyltetrazolium bromide (MTT) assay (Sigma Chemical Co, St Louis, MO), and cellular uptake of the two formulations was investigated with fluorescence microscopy and flow cytometry.

\section{Materials and methods Materials}

For preparation of the SMEDDS formulation, curcumin was purchased from Sigma-Aldrich Corporation (St Louis, MO). Capryol ${ }^{\text {TM }}$ 90, Labrafil ${ }^{\circledR}$ M1944CS, Labrasol ${ }^{\circledR}$, Plurol $^{\circledR}$ Oleique CC 497, and Transcutol ${ }^{\circledR}$ HP were purchased from Gattefosse (Saint-Priest, France). Cremophor ${ }^{\circledR}$ EL was obtained from BASF (Ludwigshafen, Germany). Emulsifier OP, 1,2-propanediol, and Tween ${ }^{\circledR} 80$ were purchased from Guangcheng Chemical Co, Ltd (Tianjin, China). Ethyl oleate and polyethylene glycol (PEG) 400 were purchased from Shanghai Chemical Co, Ltd (Shanghai, China). Ethanol was obtained from Fuyu Fine Chemical Co, Ltd (Tianjin, China). Castor oil and isopropyl myristate were purchased from Sinopharm Chemical Reagent Co, Ltd (Shanghai, China). Folate-PEG-cholesterol (F-PEG-Chol) was presented by Professor Guangya Xiang (School of Pharmacy, Huazhong University of Science and Technology, Wuhan, Hubei, China). For the cell culture experiment, folate-free Roswell Park Memorial Institute 1640 medium and Gibco ${ }^{\circledR}$ trypsinethylenediaminetetraacetic acid were purchased from Life Technologies (Carlsbad, CA). Characterized fetal bovine serum was purchased from Hangzhou Sijiqing Biological Engineering Materials Co, Ltd (Hangzhou, China). Hela (human uterine cervix cancer cell line) and HT-29 (human colon carcinoma cell line) were purchased from the cell bank of the Chinese Academy of Science (Beijing, China). The MTT assay was purchased from Sigma-Aldrich.

\section{SMEDDS formulation optimization}

\section{Solubility studies}

Solubility studies were conducted by placing an excess amount of curcumin in a $2 \mathrm{~mL}$ tube containing $1 \mathrm{~mL}$ of oil, surfactant, and cosurfactant, as shown in Table 1. The mixture was then shaken in a water bath shaker at room temperature for 48 hours to get to equilibrium. The equilibrated sample was centrifuged at $12,000 \mathrm{rpm}$ for 10 minutes, followed by filtration through a membrane filter $(0.45 \mu \mathrm{m})$ to remove the undissolved curcumin. The supernatant was taken and diluted with methanol for quantification of curcumin by high-performance liquid chromatography system (Agilent 1200 Infinity series; Agilent Technologies, Santa Clara, CA). 
Table I Solubility of curcumin in various vehicles

\begin{tabular}{|c|c|c|c|c|c|}
\hline Oils & $\begin{array}{l}\text { Solubility } \\
(\mathrm{mg} / \mathrm{mL})^{\mathrm{a}}\end{array}$ & Surfactants & $\begin{array}{l}\text { Solubility } \\
(\mathrm{mg} / \mathrm{mL})^{\mathrm{a}}\end{array}$ & Cosurfactants & $\begin{array}{l}\text { Solubility } \\
(\mathrm{mg} / \mathrm{mL})^{\mathrm{a}}\end{array}$ \\
\hline Ethyl oleate & $1.04 \pm 0.02$ & Labrasol $^{\circledR}$ & $99.30 \pm 1.73$ & I,2-propanediol & $2.68 \pm 0.25$ \\
\hline Castor oil & $1.56 \pm 0.47$ & Cremophor $^{\circledR}$ EL & $65.83 \pm 4.80$ & Ethanol & $5.98 \pm 0.63$ \\
\hline Isopropyl myristate & $0.51 \pm 0.05$ & Emulsifier OP & $5.16 \pm 1.03$ & PEG 400 & $159.78 \pm 0.48$ \\
\hline Capryol ${ }^{\mathrm{TM}} 90$ & $9.43 \pm 0.80$ & Tween $^{\circledR} 80$ & $4.86 \pm 1.15$ & Plurol ${ }^{\otimes}$ Oleique CC497 & $1.36 \pm 0.13$ \\
\hline Labrafi $^{\otimes}$ MI944CS & $3.17 \pm 0.13$ & & & Transcutol ${ }^{\circledR} \mathrm{HP}$ & $140.56 \pm 3.42$ \\
\hline
\end{tabular}

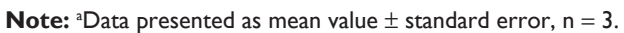

Abbreviation: PEG, polyethylene glycol.

The high-performance liquid chromatography method used a phenomenex- $\mathrm{C}_{18}$ column $(5 \mu \mathrm{m}, 4.6 \mathrm{~mm} \times 250 \mathrm{~mm})$ at room temperature, and the mobile phase was a mixture of methanol:water (containing 3.6\% glacial acetic acid) (73:27 volume/volume). The flow rate was set at $1.0 \mathrm{~mL} /$ minute and the analysis wavelength was at $428 \mathrm{~nm}$.

\section{Construction of ternary phase diagrams}

Ternary phase diagrams were constructed in order to obtain the concentration range of components for the existing region of microemulsions. ${ }^{14}$ The effect of various oils on the microemulsion formation was studied by constructing ternary phase diagrams with Capryol 90 and Labrafil M1944CS at the oil phase, with Cremophor EL as the surfactant, and Transcutol HP as the cosurfactant. When Capryol 90 was fixed at the oil phase, the influence of various surfactants on the microemulsion formation with Transcutol HP as cosurfactant and the influence of various cosurfactants on the microemulsion formation with Cremophor EL as surfactant were evaluated by constructing a ternary phase diagram.

\section{Preparation and optimization of CUR-SMEDDS formulations}

Blank SMEDDS formulations were obtained by mixing the oil with surfactant and cosurfactant, which were selected by ternary phase diagrams under a magnetic stirring at $400 \mathrm{rpm} /$ minute for 3 minutes at room temperature.
Curcumin was added to blank SMEDDS and mixed by gentle vortexing until a transparent preparation was obtained, then the CUR-SMEDDS was prepared. In this study, a simplex lattice experiment design was used to optimize the compositions of SMEDDS formulation. The Simplex-Lattice experiment design for a three-component system was represented by an equilateral triangle in a two-dimensional space..$^{15,16}$ Seven batches of CUR-SMEDDS were prepared as shown in Table 2.

\section{Synthesis of lipophilic folate derivatives and optimization of CUR-FSMEDDS}

Two lipophilic derivatives, folate-PEG-distearoylphosphatidylethanolamine (F-PEG-DSPE) and folate-PEG-cholesteryl hemisuccinate (F-PEG-CHEMS), were synthesized based on established methods. ${ }^{13,17,18}$ F-PEG-DSPE, F-PEG-CHEMS, or F-PEG-Chol was added to CUR-SMEDDS formulations as a surfactant. It has been previously reported that due to the existence of receptors such as lectin or transferrin receptors on the intestinal mucosa, relative ligands such as lectin and transferrin-modified nanoparticulate delivery systems could enhance the intestinal absorption of the drug through specific binding. ${ }^{19-21}$ Thus, it could be inferred that the folate-modified carriers would improve the absorption in the colon by the encapsulated drug binding with folate receptors on normal colorectal mucosa. ${ }^{10}$ The effect of different folate derivatives on the absorption in the colon of curcumin in FSMEDDS

Table 2 Actual and transformed values, mean particle size, and solubility of seven different formulations per Simplex-Lattice design

\begin{tabular}{|c|c|c|c|c|c|}
\hline \multirow{2}{*}{$\begin{array}{l}\text { Formulation } \\
\text { number }\end{array}$} & \multicolumn{3}{|c|}{ Formulation components/transformed fraction values } & \multirow{2}{*}{$\begin{array}{l}\text { Solubility } \\
(\mathrm{mg} / \mathrm{g})^{\mathrm{a}}\end{array}$} & \multirow{2}{*}{$\begin{array}{l}\text { Mean particle } \\
\text { size }(\mathrm{nm})^{\mathrm{a}}\end{array}$} \\
\hline & Surfactant & Cosurfactant & Oil & & \\
\hline I & $60 \% / 1$ & $30 \% / 0$ & $10 \% / 0$ & $72.7 I \pm 1.4 I$ & $29.13 \pm 0.7 \mid$ \\
\hline 2 & $30 \% / 0$ & $60 \% / 1$ & $10 \% / 0$ & $73.18 \pm 2.18$ & $121.50 \pm 12.02$ \\
\hline 3 & $30 \% / 0$ & $30 \% / 0$ & $40 \% / 1$ & $50.12 \pm 0.83$ & $36.37 \pm 5.44$ \\
\hline 4 & $45 \% / 0.5$ & $45 \% / 0.5$ & $10 \% / 0$ & $63.76 \pm 6.81$ & $28.16 \pm 0.07$ \\
\hline 5 & $45 \% / 0.5$ & $35 \% / 0$ & $25 \% / 0.5$ & $65.34 \pm 7.48$ & $216.35 \pm 14.14$ \\
\hline 6 & $30 \% / 0$ & $45 \% / 0.5$ & $25 \% / 0.5$ & $62.60 \pm 1.41$ & $186.03 \pm 3.39$ \\
\hline 7 & $40 \% / 0.33$ & $40 \% / 0.33$ & $20 \% / 0.33$ & $58.45 \pm 3.78$ & $232.3 \pm 1.06$ \\
\hline
\end{tabular}

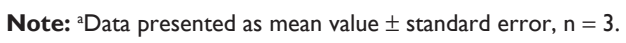


formulations was thus studied using the established in situ colon perfusion method in rats..$^{22,23}$

Rats were fasted overnight with free access to water before the experiment. The rat was anesthetized by an intraperitoneal injection of $1 \%$ sodium pentobarbital $(0.4 \mathrm{~mL} / 100 \mathrm{~g}$ body weight) and was placed under an infrared lamp to keep body temperature normal. Upon verification of the loss of pain reflexes, the abdomen was opened with a middle longitudinal incision about $3 \mathrm{~cm}$ long. After the abdominal cavity was opened, the colon segment in perfusion was exposed and incisions were made on both sides of the segment. It was rinsed with physiological saline and then connected to a constant-flow pump (BT00-100M; Baoding Longer Precision Pump Co, Ltd, Baoding, China) with catheters to the perfusion system. Curcumin-loaded microemulsion $(25 \mathrm{~mL})$ was prepared by dispersing CUR-SMEDDS or CUR-FSMEDDS containing different types and concentrations of lipophilic folate derivatives in a Krebs-Ringer buffer solution (SigmaAldrich) at $37^{\circ} \mathrm{C}$. Perfusion with the curcumin dose of $50 \mathrm{mg} / \mathrm{kg}$ was introduced into colon segment loops with the pump at a flow rate of $2.5 \mathrm{~mL} /$ minute; both ends of the loop were ligated. The entire surgical area was covered with a piece of sterilized absorbent gauze wetted with normal saline. After 6 hours, the effluent solution in the loop was collected and diluted by Krebs-Ringer buffer solution for determination.

\section{Characterization of CUR-FSMEDDS}

\section{Morphology}

The morphology of CUR-FSMEDDS was observed under transmission electron microscope (JEM-1200EX; JEOL Ltd, Tokyo, Japan). CUR-FSMEDDS was diluted with distilled water (1:100) and gently mixed, and then stained with a $2 \%$ aqueous solution of phosphotungstic acid and allowed to dry before observation under the transmission electron microscope.

\section{Droplet size and zeta potential determination} CUR-FSMEDDS formulation (1 $\mathrm{mL})$ was diluted with $100 \mathrm{~mL}$ of deionized water under constant stirring. The droplet size distribution and zeta potential of the resultant microemulsion was determined by a particle size and zeta potential analyzer (Delsa ${ }^{\mathrm{TM}} \mathrm{Nano}$; Beckman Coulter Inc, Brea, CA).

\section{Release of curcumin from FSMEDDS-filled colon-targeted capsules}

CUR-FSMEDDS equivalent to $1 \mathrm{mg}$ of curcumin were filled into colon-targeted capsules for rats (Qiangji Pharmaceutical
Factory, Chaozhou, China) without shell damage. Release studies of CUR-FSMEDDS capsules in vitro were carried out in $150 \mathrm{~mL}$ of $\mathrm{pH}$ progression medium at $37^{\circ} \mathrm{C} \pm 0.5^{\circ} \mathrm{C}$, with the paddle operated at $50 \mathrm{rpm} .^{24}$

The drug release from FSMEDDS was designed as follows: hour 0-2: drug release was carried out in the simulated gastric fluid ( $0.1 \mathrm{~N}$ hydrochloride) with $\mathrm{pH} 1.2$ as dissolution medium; hour 2-5: drug release was performed in the simulated intestinal fluid (6.8045 g monopotassium phosphate, $118 \mathrm{~mL}$ of $0.2 \mathrm{~N}$ sodium hydroxide in $1000 \mathrm{~mL}$ of distilled water) with pH 6.8 as dissolution medium; hour 5-24: drug release was performed in the simulated colonic fluid $(6.8 \mathrm{~g}$ monopotassium phosphate, $291 \mathrm{~mL}$ of $0.1 \mathrm{~N}$ sodium hydroxide in $1000 \mathrm{~mL}$ of distilled water) with $\mathrm{pH} 7.4$.

Samples $(3 \mathrm{~mL})$ were withdrawn and replaced with fresh media at 60, 120, 180, 240, 300, 305, 310, 320, 330, 345, 360, and 390 minutes. Samples were then filtered using a $0.45 \mu \mathrm{m}$ filter and analyzed by an ultraviolet spectrophotometer (UV-2102; Shanghai Instrument Ltd, Shanghai, China). Three separate replicate studies were conducted for each of the formulations and data presented as mean \pm standard deviation $(n=3)$.

\section{Cell culture}

HT-29 and Hela cell lines were maintained in folate-free Roswell Park Memorial Institute 1640 media supplemented with $10 \%$ fetal bovine serum. The cells were incubated at $37^{\circ} \mathrm{C}$ with $5 \%$ carbon dioxide. After reaching confluence, the cells were detached from the flask with trypsin-ethylenediaminetetraacetic acid. The cell suspension was centrifuged at $800 \mathrm{rpm}$ for 3 minutes and then resuspended in the growth medium for further experiments.

\section{Cytotoxicity studies}

Cytotoxicity of SMEDDS was determined by an MTT assay. ${ }^{11}$ Hela and HT-29 cells (5000/well) were seeded in a 96-well plate and allowed to attach for 24 hours. The medium was replaced with $100 \mu \mathrm{L}$ of fresh folate-free medium and the cells were treated with $100 \mu \mathrm{L}$ of different concentrations of free curcumin (curcumin-dimethyl sulfoxide), CUR-SMEDDS, and CUR-FSMEDDS with or without $1 \mathrm{mM}$ of free folate $(1,5,10,20,40 \mu \mathrm{M}$ curcumin/ well). After being incubated for 24 hours at $37^{\circ} \mathrm{C}$ in a carbon dioxide incubator, the medium was removed and then fresh medium was added after cells were washed three times with phosphate buffered saline. Then, $20 \mu \mathrm{L}$ of MTT $(5 \mathrm{mg} / \mathrm{mL}$ in phosphate buffered saline) was added to the cells and incubated for 4 hours at $37^{\circ} \mathrm{C}$. The medium was then removed and replaced with $150 \mu \mathrm{L}$ of dimethyl sulfoxide to dissolve 
the blue formazan crystals converted from MTT by live cells. The optical density of each well was measured using a microplate reader (Model 680; Bio-Rad Laboratories, Hercules, CA) equipped with a $570 \mathrm{~nm}$ filter. Triplicate samples were analyzed for each experiment.

\section{Cellular uptake studies}

\section{Qualitative cellular uptake study}

Coumarin 6 (Sigma-Aldrich) was used as a model hydrophobic fluorescent probe to be encapsulated in SMEDDS formulation. HT-29 and Hela cells were seeded in a 24-well plate at a density of $10^{5}$ cells/well and allowed to attach for 24 hours. By replacing the contents with fresh medium, the cells were incubated with nontargeted Coumarin 6-loaded SMEDDS (Coumarin 6-SMEDDS) or Coumarin 6-FSMEDDS at $37^{\circ} \mathrm{C}$ for $0.5,1,2,5$, and 24 hours, respectively. To determine the role of folate receptor binding, $1 \mathrm{mM}$ of free folate was added to the media in the folate receptor blocking group (Coumarin 6-FSMEDDS) and incubated for 1 hour before adding drugs at different time intervals. All the wells were treated with $15 \mu \mathrm{g} / \mathrm{mL}$ of Coumarin 6 for each formulation. ${ }^{25}$ At the end of incubation, the cells were washed three times with cold phosphate buffered saline to remove residual drugs, and the fluorescence images of Coumarin 6 in different cells were captured under a fluorescence microscope (BX 51; Olympus Corporation, Tokyo, Japan) using a blue filter.

\section{Cellular uptake by flow cytometry}

The cellular uptake of Coumarin 6 in SMEDDS and FSMEDDS formulations (with or without $1 \mathrm{mM}$ folate) was formed by fluorescence-activated cell sorting analysis. Cells were seeded in a 6-well plate at a density of $10^{6}$ cells/well. After reaching $90 \%$ confluence, $15 \mu \mathrm{g} / \mathrm{mL}$ of Coumarin 6 in different formulations was added and incubated at $37^{\circ} \mathrm{C}$ for 2 hours. Intracellular Coumarin 6 fluorescence was analyzed with a flow cytometer (FACSCalibur ${ }^{\mathrm{TM}}$ system; Becton, Dickinson, and Company, Franklin Lakes, NJ).

\section{Statistical analysis}

Statistical data analyses were performed using Student's $t$-test with the aid of IBM SPSS (v16.0; SPSS Inc, Chicago, IL). A value of $P<0.05$ was considered statistically significant.

\section{Results and discussion Solubility studies}

To develop a SMEDDS formulation for oral delivery of poorly water-soluble curcumin, a suitable oil, surfactant, and cosurfactant needed to be chosen. The solubility of curcumin in various vehicles are presented in Table 1. As shown in Table 1, curcumin showed good solubility in the oils Capryol $90(9.43 \pm 0.80 \mathrm{mg} / \mathrm{mL})$ and Labrafil M1944CS $(3.17 \pm 0.13 \mathrm{mg} / \mathrm{mL})$.

Surfactants Labrasol and Cremophor EL showed maximum drug solubilization $(99.30 \pm 1.73 \mathrm{mg} / \mathrm{mL}$ and $65.83 \pm 4.80 \mathrm{mg} / \mathrm{mL}$, respectively). Cosurfactants Transcutol HP (140.56 $\pm 3.42 \mathrm{mg} / \mathrm{mL})$ and PEG $400(159.78 \pm 0.48 \mathrm{mg} / \mathrm{mL})$ exhibited higher solubility for curcumin. The high solubility in PEG 400, Cremophor EL, and Labrasol might be due to the ability of curcumin to form a hydrogen bond with the polyethylene oxide groups in above materials. ${ }^{26}$ The above excipients with high solubility for curcumin were used to construct the ternary phase diagrams.

\section{Construction of ternary phase diagrams}

Drug loading capability is the main factor when screening the oil phase. Curcumin showed higher solubility in Capryol 90 and Labrafil M1944CS. Their phase behaviors were compared by constructing ternary phase diagrams. The phase diagrams of the systems containing Cremophor EL as surfactant, Transcutol HP as cosurfactant, and different oils (Capryol 90 and Labrafil M1944CS) are shown in Figure 1A and B. A larger self-microemulsifying region was found, as shown in Figure 1A. Hence, Capryol 90 was selected at oil phase. Two phase diagrams were constructed with Capryol 90 as the oil, Transcutol HP as cosurfactant, and different surfactants (Cremophor EL or Cremophor EL:Labrasol [1:1]). As shown in Figure 1C, the self-microemulsion region of the formulation containing Cremophor EL was larger than that containing Cremophor EL:Labrasol (1:1). Therefore, the desirable surfactant should be Cremophor EL.

As to the selection of a cosurfactant, Capryol 90 and Cremophor EL were used as oil phase and surfactant, respectively. As shown in Figure 1D and E, the solubility of curcumin in PEG 400 was higher than that in Transcutol HP or in ethanol. However, compared with Transcutol HP, PEG 400 had relatively higher hydrophilic properties, which could increase the risk of destroying the microemulsion. ${ }^{26}$ In addition, the self-microemulsion region of Transcutol HP was larger compared with that of PEG 400 or ethanol. Therefore, Transcutol HP was selected as the cosurfactant.

\section{Preparation and optimization of CUR-SMEDDS formulations}

A Simplex-Lattice design was used to optimize the composition of CUR-SMEDDS. In view of the feasibility of 

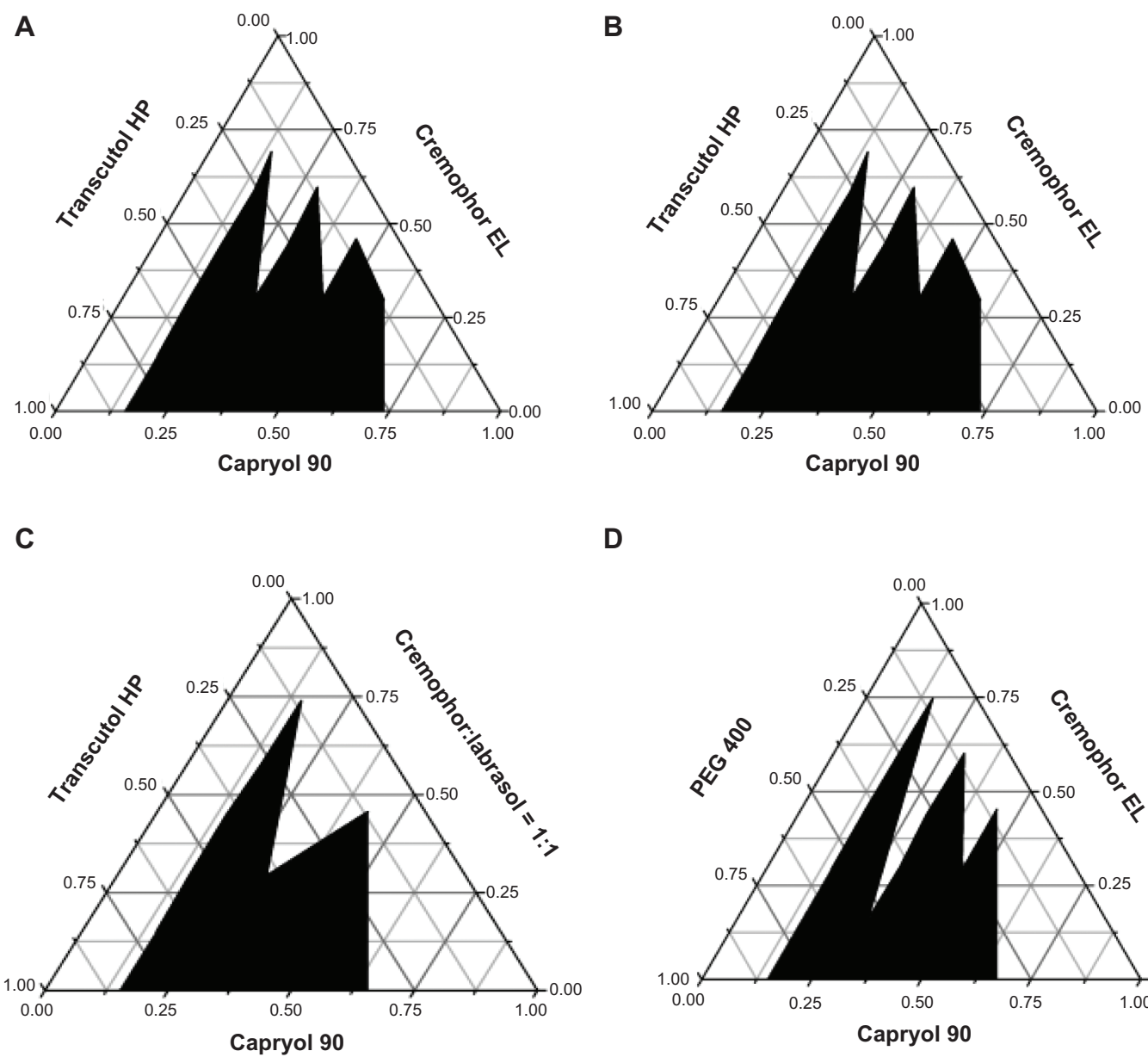

D
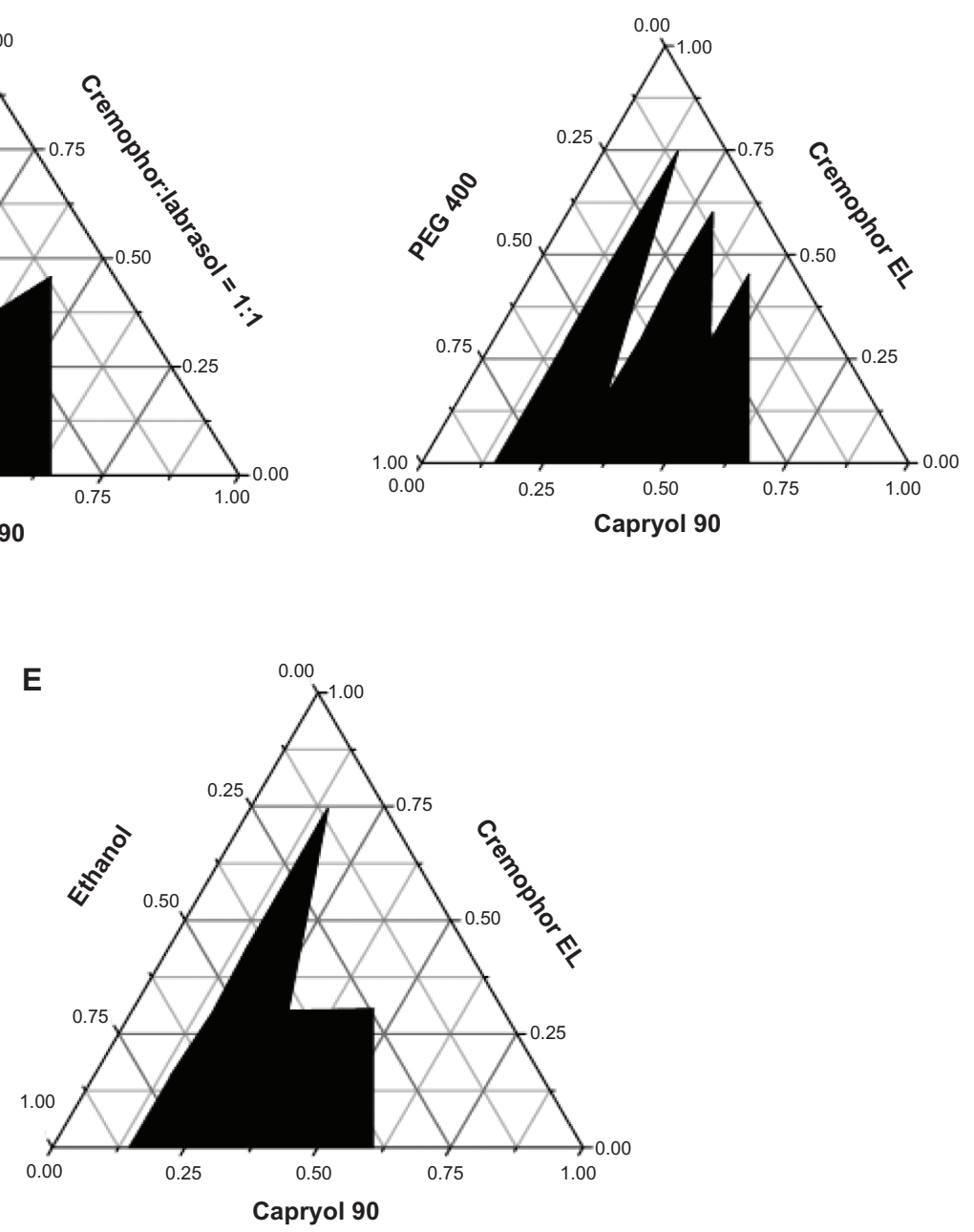

Figure I Ternary phase diagrams studies for selecting of oil, surfactant, and cosurfactant.

SMEDDS formation, according to the ternary phase diagrams shown in Figure 1, the ranges of the three factors were selected as follows: surfactant percentage (X1), 30\%-60\%; cosurfactant percentage (X2), 30\%-60\%; oil percentage (X3), 10\%-40\%. Seven formulations containing curcumin were conducted (Table 2). In order to achieve a high drug loading and a uniform droplet size $(<100 \mathrm{~nm})$, solubility and mean particle size of the seven formulations were selected as evaluation indexes.

The results were processed with a MATLAB ${ }^{\circledR} 7.0$ dataprocessing system (MathWorks, Natick, MA) and the equations for solubility and mean particle size were as follows: 
- $\mathrm{Y}_{\text {solubility }}=50.16+14.79[\mathrm{CoS}]-543.59[\mathrm{O}]-88.89[\mathrm{~S}]$

$[\mathrm{CoS}]+1665.8[\mathrm{~S}][\mathrm{O}]+1533.6[\mathrm{CoS}][\mathrm{O}]-4971.1[\mathrm{~S}]$ [CoS][O], $\left(\mathrm{R}^{2}=0.9999\right)$

- $\mathrm{Y}_{\text {particle size }}=242.3+647.9222[\mathrm{CoS}]+39.0667[\mathrm{O}]$ $-8268.4[\mathrm{~S}][\mathrm{CoS}]-10358[\mathrm{~S}][\mathrm{O}]-13758[\mathrm{CoS}]$ $[\mathrm{O}]+61727[\mathrm{~S}][\mathrm{CoS}][\mathrm{O}],\left(\mathrm{R}^{2}=0.9999\right)$.

In the two equations, $\mathrm{CoS}$ represents the cosurfactant, $\mathrm{S}$ the surfactant, and $\mathrm{O}$ the oil. All the obtained coefficients $\mathrm{R}^{2}$ are larger than 0.95 , indicating that over $95 \%$ of the variation in response could be explained with this model, and the agreement of fit to the model was confirmed. As shown in Table 2, particle size increased and the solubility of curcumin decreased with the increase of the ratio of oil in the formulation. In order to obtain suitable particle size and high solubility of curcumin, the percentage of oil was set at $10 \%{ }^{27}$ Based on the two equations, contour plots of solubility and mean particle size were constructed (Figure 2). Trace contours were constructed when $\mathrm{Y}_{\text {solubility }}$ was equal to 60,65 , and $70 \mathrm{mg} / \mathrm{g}$ as shown in Figure 2A. In Figure 2B, three mean particle size curves stood for $10 \mathrm{~nm}, 50 \mathrm{~nm}$, and $100 \mathrm{~nm}$. The optimized formulation was chosen by superimposing the contour plots of the two responses (Figure 2C). The common section between $Y_{\text {particle size }}$ (located at the field of $10-50 \mathrm{~nm}$ ) and $Y_{\text {solubility }}$ (located at the scope of $65-70 \mathrm{mg} / \mathrm{g}$ ) was the best area for the concentrations of surfactant and cosurfactant.

Based on solubility for curcumin and the mean particle size of the formed microemulsion, the composition of optimized formulation was chosen as follows: $57.5 \%$ surfactant (Cremophor EL), 32.5\% cosurfactant (Transcutol HP), and $10 \%$ oil (Capryol 90). To confirm the model's adequacy for prediction, three batches of CUR-SMEDDS under the optimum composition were prepared, and the two responses $\left(\mathrm{Y}_{\text {solubility }}\right.$ and $\mathrm{Y}_{\text {particle size }}$ ) were evaluated. The results presented in Table 3 show the predicted values of mean particle size and solubility of SMEDDS calculated by equations were close to those obtained from the experiment.

\section{Synthesis of lipophilic folate derivatives}

The structures of the synthesized F-PEG-DSPE and F-PEGCHEMS were confirmed by hydrogen-1 nuclear magnetic resonance, and the spectrograms for the two materials are shown in Figure 3. For F-PEG-CHEMS, hydrogen-1 nuclear magnetic resonance analysis showed principal peaks (in ppm) related to the folate moiety ( 8.11 [double peaks; d], 7.63 [d], 6.93 [three peaks; t], 6.63 [d], 4.48 [d], 4.30 [mixed peaks; m]), the PEG moiety (3.65 [m]) and the CHEMS moiety (5.34 [d], $4.5[\mathrm{~m}], 0.65-2.30[\mathrm{~m}])$, which was similar to a previous report. ${ }^{18}$
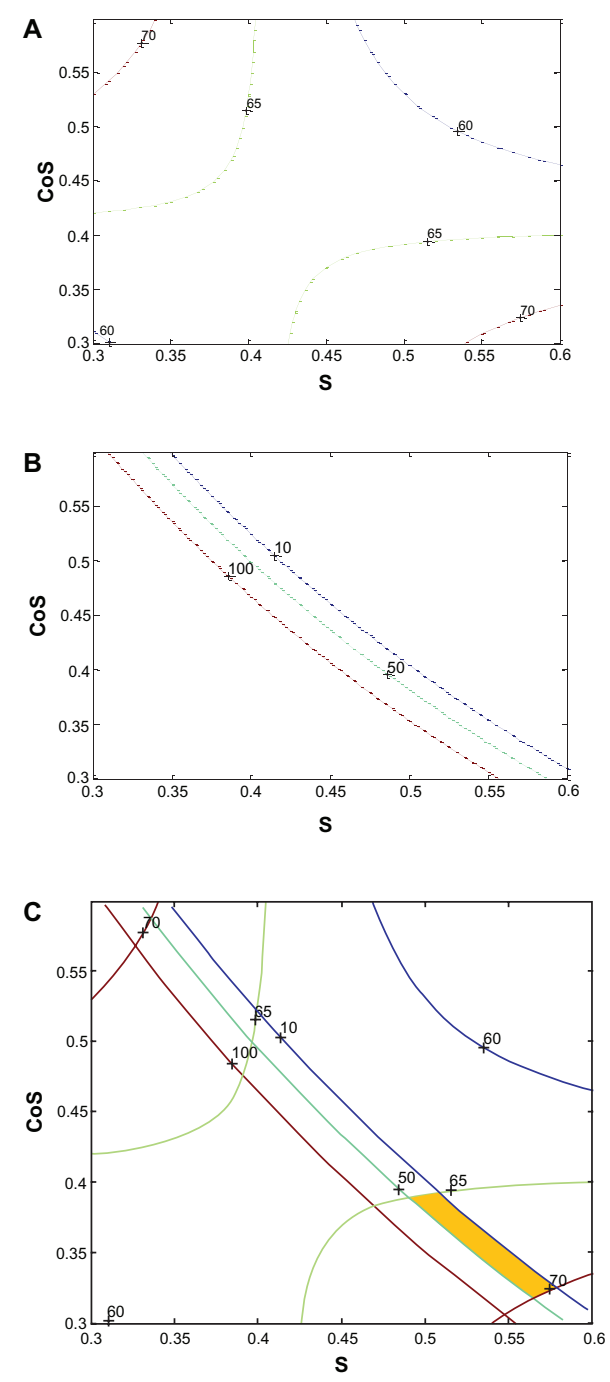

Figure 2 The contour plots of response for the contour plot of mean particle size (A), the contour plot of solubility (B), and the mixed contour plot of mean particle size and solubility $(\mathbf{C})$.

Abbreviations: S, surfactant; CoS, cosurfactant.

Moreover, the structure of F-PEG-DSPE was corroborated by hydrogen-1 nuclear magnetic resonance, and the main peaks (in $\mathrm{ppm})$ for the folate moiety ( 8.63 [small peaks; s], 7.68 [d], 6.62 [d], 4.47 [d]), the PEG moiety (3.65 [m]) and the DSPE moiety (0.85 [t], 1.23 [s], 1.49 [d], 2.24 [d]) confirmed the structure of F-PEGDSPE, which was in accordance with a previous study. ${ }^{28}$

Table 3 The predicted values and the experimental results of the curcumin-loaded self-microemulsifying drug delivery system prepared under the optimum conditions

\begin{tabular}{llll}
\hline Response & $\begin{array}{l}\text { Predicted } \\
\text { value }\end{array}$ & $\begin{array}{l}\text { Experimental } \\
\text { value }^{\mathrm{a}}\end{array}$ & Bias (\%) \\
\hline Solubility $(\mathrm{mg} / \mathrm{g})$ & 69.95 & $67.32 \pm 0.92$ & 3.91 \\
Particle size $(\mathrm{nm})$ & 22.43 & $24.6 \pm 0.42$ & 8.82 \\
\hline
\end{tabular}

Notes: Bias $(\%)=([$ predicted value - experimental value] $/$ experimental value $) \times 100$; adata presented as mean value \pm standard error, $n=3$. 


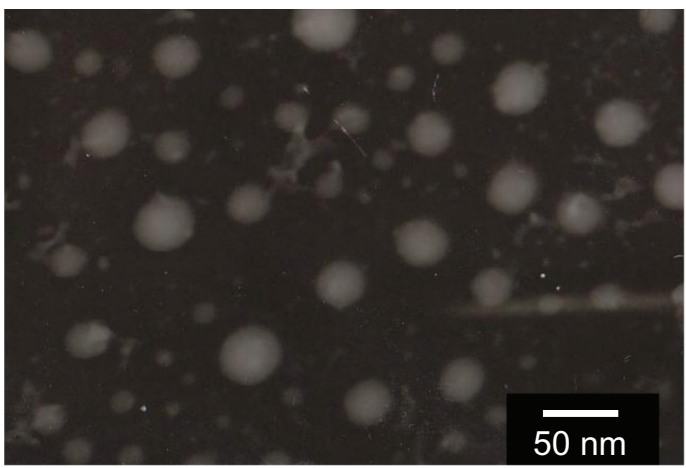

Figure 3 Transmission electron microscope micrographs of curcumin-loaded selfmicroemulsifying drug delivery system with the scale bar for the image representing $50 \mathrm{~nm}$.

\section{Optimization of CUR-FSMEDDS}

Folate receptor is overexpressed in many tumors and enables the endocytosis of folate-conjugated carriers. Thus, folate is an attractive tumor-targeting ligand in the cell-specific delivery systems. ${ }^{29}$ Currently, lipophilic folate derivatives, such as F-PEG- DSPE, F-PEG-CHEMS, and F-PEG-Chol were used to enhance the accumulation of formulations in the tumor. ${ }^{12,17,30}$ Except for these, folate receptor was proven to exist in normal colorectal mucosa, which could lead to the endocytosis of folate material and an increase in the absorption of drug in the colon. ${ }^{10}$ In order to evaluate the effect of different types and concentrations of lipophilic folate derivatives in SMEDDS on the absorption of curcumin in colon mucosa, a colon perfusing experiment in rats was performed. ${ }^{27}$

CUR-FSMEDDS was prepared by adding lipophilic folate derivatives into the mixture of surfactant, cosurfactant, and oil. The absorption percentage of curcumin in the colon for 6 hours was calculated using the formula: $\mathrm{P}=\left(\mathrm{C}_{0} \mathrm{~V}_{0}\right)$ $\left.\mathrm{C}_{1} \mathrm{~V}_{1}\right) \times 100 \%$, where $\mathrm{C}_{0} \mathrm{~V}_{0}$ is the original concentration and volume and $\mathrm{C}_{1} \mathrm{~V}_{1}$ is the resulting concentration and volume. When the weight ratio of folate conjugated materials to Cremophor EL was at 3:100, the absorption percentage of the formulation containing F-PEG-CHEMS showed no significant difference compared with that containing F-PEG-DSPE or F-PEG-Chol $(P>0.05)$, but showed a significant difference compared with CUR-SMEDDS $(P<0.05)$ (Table 4). Moreover, the two negative charges in F-PEG-DSPE and a carbamate linker in F-PEG-Chol could limit their hydrolytic stability. ${ }^{18}$ Thus, F-PEG-CHEMS was chosen for concentration screening. Three weight ratios of F-PEG-CHEMS to Cremophor EL $(0.5: 100,1: 100$, and 3:100) were evaluated, and the formulation in which the weight ratio of F-PEG-CHEMS to Cremophor EL was 1:100 had the maximum absorption percentage among the studied preparations $(P<0.05)$. Therefore, the final formulation of FSMEDDS was comprised of $57.5 \%$ Cremophor EL, $32.5 \%$ Transcutol HP, 10\% Capryol 90 with a small amount of F-PEG-CHEMS (the weight ratio of folate materials to Cremophor EL was 1:100). After the incorporation of F-PEG-CHEMS, the solubility of curcumin in FSMEDDS was $66.59 \pm 1.21 \mathrm{mg} / \mathrm{g}$, which was not significantly different compared with that in SMEDDS $(67.32 \pm 0.92 \mathrm{mg} / \mathrm{g})$ $(P>0.05)$. However, the solubility of curcumin in the aqueous medium was about $11 \mathrm{ng} / \mathrm{g} .{ }^{31,32}$ Therefore, it could be concluded that FSMEDDS increased the solubility of curcumin in water more than $6 \times 10^{6}$-fold.

\section{Characterization of CUR-FSMEDDS}

CUR-FSMEDDS can form into microemulsion when diluted with distilled water. As shown in the transmission electron microscope picture (Figure 3), the microemulsion droplets appeared spherical without aggregation. The parameters for physicochemical characters of the optimized formulation are shown in Table 5. For blank FSMEDDS, droplet size was significantly increased with the incorporation of F-PEG-CHEMS $(P<0.05)$. The long PEG-spacer in F-PEG-CHEMS dispersing into the emulsifying membrane layer (composed of surfactant and cosurfactant) might lead to increased droplet size. As seen in Table 5, the addition of curcumin in SMEDDS and

Table 4 The absorption percentage of curcumin in different formulations with the established in situ colon perfusion method in rats for 6 hours

\begin{tabular}{ll}
\hline Formulations & Absorption percentage (\%) $^{\mathrm{a}}$ \\
\hline CUR-SMEDDS without folate material & $58.41 \pm 7.26$ \\
CUR-FSMEDDS with weight ratio of F-PEG-CHEMS to Cremophor ${ }^{\circledast}$ EL at 3:100 & $67.14 \pm 3.72$ \\
CUR-FSMEDDS with weight ratio of F-PEG-DSPE to Cremophor ${ }^{\circledast}$ EL at 3:100 & $62.66 \pm 4.33$ \\
CUR-FSMEDDS with weight ratio of F-PEG-Chol to Cremophor ${ }^{\circledast}$ EL at 3:100 & $64.96 \pm 3.13$ \\
CUR-FSMEDDS with weight ratio of F-PEG-CHEMS to Cremophor ${ }^{\circledast}$ EL at 0.5:100 & $62.11 \pm 2.16$ \\
CUR-FSMEDDS with weight ratio of F-PEG-CHEMS to Cremophor ${ }^{\circledast}$ EL at I:100 & $73.38 \pm 3.12$ \\
\hline
\end{tabular}

Note: aData presented as mean value \pm standard error, $\mathrm{n}=3$.

Abbreviations: CUR-FSMEDDS, curcumin-loaded folate-modified self-microemulsifying drug delivery system; CUR-SMEDDS, curcumin-loaded self-microemulsifying drug delivery system; F-PEG-CHEMS, folate-polyethylene glycol-cholesteryl hemisuccinate; F-PEG-Chol, folate-polyethylene glycol-cholesterol; F-PEG-DSPE, folate-polyethylene glycol- distearoyl-phosphatidylethanolamine. 
Table 5 Mean particle size and zeta potential of different self-microemulsifying drug delivery system formulations

\begin{tabular}{llll}
\hline Samples & Mean particle size $(\mathbf{n m})^{\mathbf{a}}$ & Polydispersity index $^{\mathbf{a}}$ & ${\text { Zeta potential }(\mathbf{m V})^{\mathbf{a}}}^{\text {Blank SMEDDS }}$ \\
Blank FSMEDDS & $23.7 \pm 0.78$ & $0.273 \pm 0.008$ & $-1.65 \pm 0.68$ \\
Curcumin-loaded SMEDDS & $27.3 \pm 0.64$ & $0.046 \pm 0.004$ & $-1.93 \pm 0.39$ \\
Curcumin-loaded FSMEDDS & $27.6 \pm 0.42$ & $0.32 \pm 0.005$ & $-5.56 \pm 0.97$ \\
\hline
\end{tabular}

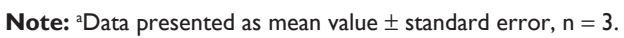

Abbreviations: FSMEDDS, folate-modified self-microemulsifying drug delivery system; SMEDDS, self-microemulsifying drug delivery system.

FSMEDDS significantly increased droplet size after diluting with distilled water $(P<0.05)$, which was in accordance with another study. ${ }^{27}$ The zeta potential is an electrostatic value measured by surface electrostatic double layer of droplets. As shown in Table 5, the absolute zeta potential value of CURSMEDDS was significantly higher than that of blank SMEDDS $(P<0.05)$. The possible reason being that the formation of intermolecular hydrogen bonds among the hydroxyl groups in curcumin and some relative groups containing oxygen or nitrogen atoms in surfactant, cosurfactant, and oil produced the change in the surface electrostatic double layer of droplets. ${ }^{33}$

\section{Release of curcumin from FSMEDDS- filled capsules for colon targeting}

The optimized SMEDDS formulations were filled volumetrically in colon-targeted gelatin capsules coated with Eudragit ${ }^{\circledR}$ S 100 (Evonik Industries, Essen, Germany).

In vitro release studies were carried out in order to evaluate the effect of colon-targeted capsules with the objective of releasing most of the drug in the colon. An ideal formulation for site-specific delivery of the drug to the colon should suppress the drug's release in the upper gastrointestinal tract and once transported to the colon, the drug should release rapidly. Figure 4 shows the drug release from the colontargeted capsules filled with CUR-FSMEDDS in simulated gastrointestinal tract fluids. At $\mathrm{pH} 1.2$ about $5 \%$ of the drug

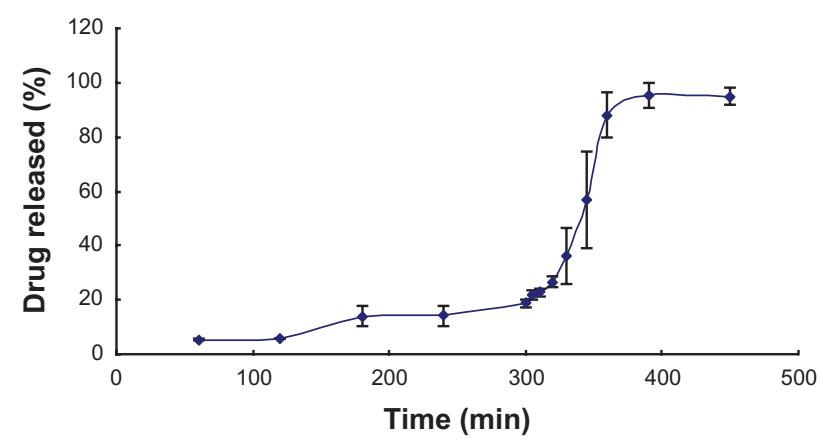

Figure 4 Dissolution profiles of curcumin from curcumin-loaded folate-modified self-microemulsifying drug delivery system colon-targeted capsules in stimulated gastrointestinal fluids of different $\mathrm{pH}$ at a speed of $50 \mathrm{rpm}$.

Note: Results are represented by mean \pm standard deviation $(n=3)$. amount was released from the capsule in the following 3 hours and (in simulated intestinal fluid with $\mathrm{pH} 6.8$ ), about $13 \%$ of curcumin was released from the capsule. In conclusion, in the first 5 hours, less drug was released from the capsules, which was attributed to the insolubility of Eudragit S 100 in low $\mathrm{pH}$. However, after the capsules were transferred into simulated colonic fluid ( $\mathrm{pH} 7.4$ ) for 150 minutes, about $77 \%$ of the drug was released from the capsules, which was due to the dissolution of capsules and the formation of curcumin microemulsion. The results indicated that drug was protected from the upper gastrointestinal tract by the colon-targeted capsules, and this formulation of curcumin could reach the colon efficiently and release the drug immediately.

\section{Cytotoxicity studies}

Cytotoxicity of blank SMEDDS, blank FSMEDDS, CURSMEDDS, CUR- FSMEDDS, free folate + CUR-SMEDDS, and free curcumin were studied using MTT assay, and their concentrations leading to $50 \%$ cell death were determined from concentration-dependent cell viability curves. As shown in Table 6 , the $50 \%$ cell death value for CUR-FSMEDDS was lower than that for CUR-SMEDDS and free curcumin $(P<0.05)$, which may be because the receptor-mediated endocytosis increased the accumulation in the cell of curcumin from FSMEDDS. ${ }^{13}$ The $50 \%$ cell death value for CURFSMEDDS increased when $1 \mathrm{mM}$ folate was first added in both Hela and HT-29 cells $(P<0.05)$. The results suggested that free folate in the medium could prevent CUR-FSMEDDS transport into cells by competitively binding to folate receptors on the cell surface. The much higher cytotoxicity of free curcumin compared with CUR-SMEDDS may be a result of when cells were exposed to free curcumin in dimethyl sulfoxide or CUR-SMEDDS for the same amount of time, leading to more rapid free curcumin uptake. ${ }^{13}$

\section{Cellular uptake studies}

Although curcumin demonstrates autofluorescence, its fluorescence intensity was weak in the preliminary experiment. Therefore, Coumarin 6 was used as a model hydrophobic 
Table 6 Cytotoxicities of various curcumin to Hela and HT-29 cells

\begin{tabular}{lcll}
\hline Treatment group (Hela) & IC $_{50}(\mu \mathbf{M})^{\mathbf{a}}$ & Treatment group (HT-29) & IC $_{50}\left(\mu \mathbf{M}^{\mathbf{a}}\right.$ \\
\hline CUR-FSMEDDS & $18.27 \pm 1.13$ & CUR-FSMEDDS & $20.57 \pm 0.78$ \\
CUR-FSMEDDS + I mM folate & $27.27 \pm 1.56$ & CUR-FSMEDDS + I mM folate & $30.31 \pm 2.7 \mathrm{I}$ \\
CUR-SMEDDS & $36.69 \pm 1.04$ & CUR-SMEDDS & $38.59 \pm 0.17$ \\
Free curcumin & $30.4 \pm 1.71$ & Free CUR & $25.62 \pm 2.23$
\end{tabular}

Note: aData presented as mean value \pm standard error, $n=3$.

Abbreviations: CUR-FSMEDDS, curcumin-loaded folate-modified self-microemulsifying drug delivery system; CUR-SMEDDS, curcumin-loaded self-microemulsifying drug delivery system; $I C_{50}, 50 \%$ cell killing; Hela cells, human uterine cervix cancer cell line; HT-29 cells, human colon carcinoma cell line.

fluorescent probe in this study. ${ }^{34}$ Uptake by HT-29 and Hela cells of microemulsions formed from SMEDDS in culture media was analyzed with fluorescence microscopy and flow cytometry. As shown in Figure 5, more FSMEDDS fluorescently-labeled cells could be clearly visualized compared with SMEDDS and the intensity of fluorescence decreased when $1 \mathrm{mM}$ folate was added to the medium, indicating folate-mediated endocytosis of FSMEDDS could be blocked by competitively binding to folate receptors on the cell surface. These microemulsions formed from SMEDDS were found to rapidly associate with folate receptor-positive HT-29 and Hela cells in the initial 30 minutes. The fluorescence intensity increased along with the extension of incubation time, and remained almost steady even after 48 hours, suggesting the
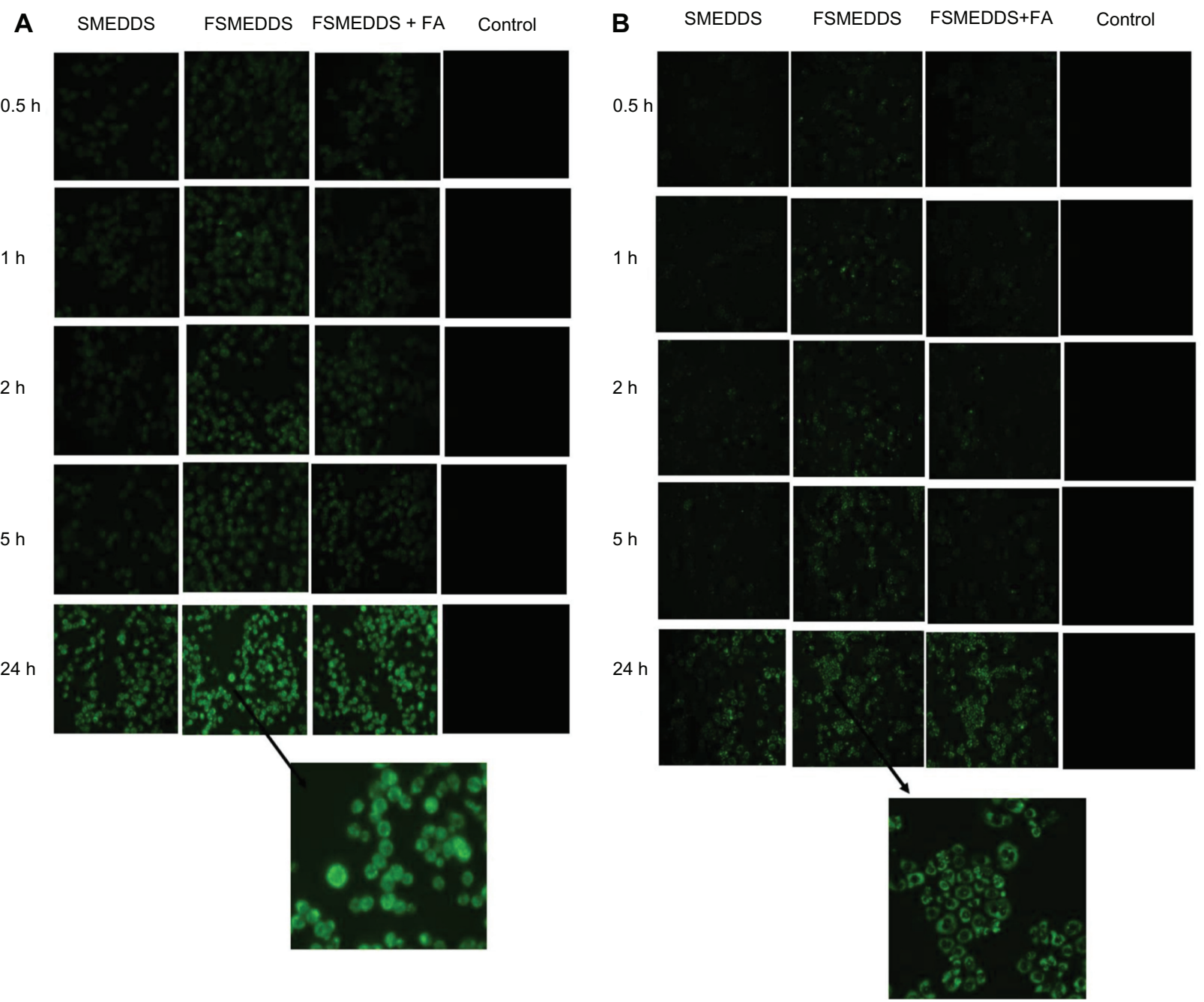

Figure 5 Fluorescence microscopy images showcasing the time dependent (0.5, I, 2, 5, and 24 hours) intracellular uptake of Coumarin 6 from Coumarin 6 -loaded self-microemulsifying drug delivery system, Coumarin 6-loaded folate-modified self-microemulsifying drug delivery system, and Coumarin 6-loaded folate-modified self-microemulsifying drug delivery system + ImM folic acid by HT-29 (human colon carcinoma cell line) (A) and Hela (human uterine cervix cancer line) cells (B), the concentration of Coumarin 6 is I5 $\mu$ g/mL. Abbreviations: FA, folic acid; FSMEDDS, folate-modified self-microemulsifying drug delivery system; h, hours; SMEDDS, self-microemulsifying drug delivery system. 


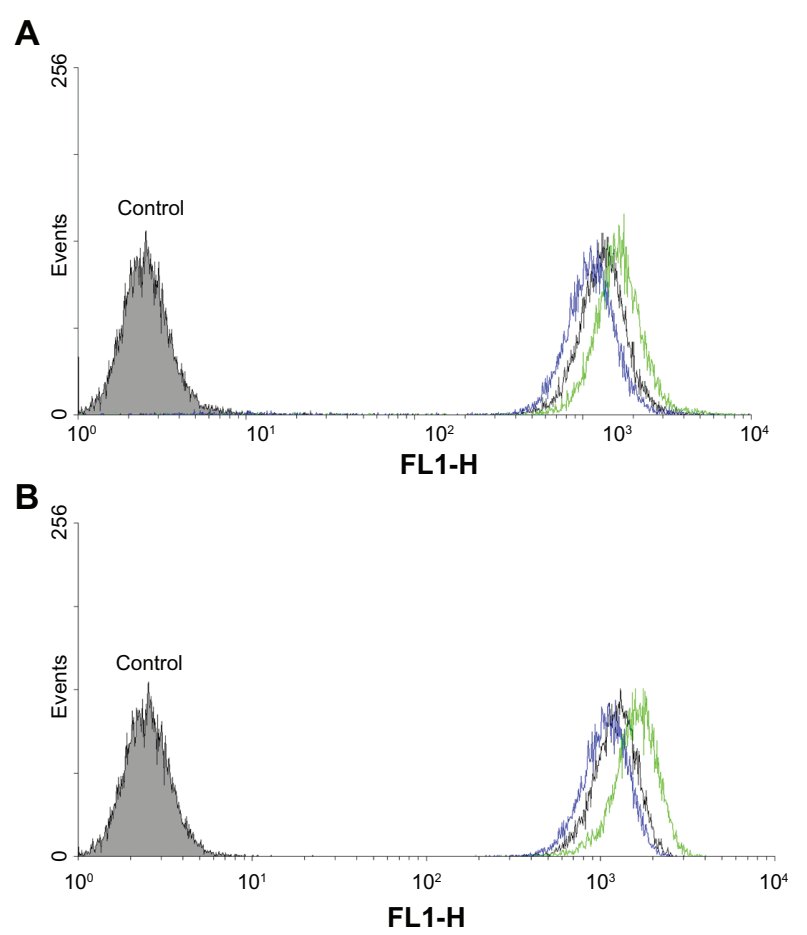

Figure 6 Flow cytometry results of HT-29 (human colon carcinoma cell line) (A) and Hela (human uterine cervix cancer cell line) (B) cells incubated with Coumarin 6-loaded folate-modified self-microemulsifying drug delivery system + I mM folate (black), Coumarin 6-loaded folate-modified self-microemulsifying drug delivery system (green), Coumarin 6-loaded self-microemulsifying drug delivery system (blue) at an equivalent Coumarin 6 concentration of $15 \mu \mathrm{g} / \mathrm{mL}$ for 2 hours at $37^{\circ} \mathrm{C}$.

retention of Coumarin 6 from SMEDDS localized inside the cells. ${ }^{35}$ Flow cytometric analysis was performed after incubation at $37^{\circ} \mathrm{C}$ for 2 hours. Similarly, the flow cytometry results in Figure 6 show that the cellular uptake of folate receptortargeted SMEDDS was much greater than that of nontargeted SMEDDS and the uptake was partly blocked by $1 \mathrm{mM}$ free folate. All of these results indicated that the CUR-FSMEDDS formulation was transported into Hela and HT-29 cells via a folate receptor-mediated endocytosis process.

\section{Conclusion}

In this study, an FSMEDDS formulation was developed which could improve the solubility of curcumin and target the folate receptor in colon cancer cells. Compositions of SMEDDS were selected with ternary phase diagrams, and the formulation of CUR-SMEDDS was optimized by a Simplex-Lattice experiment design. The effect of different folate derivatives such as F-PEG-CHEMS, F-PEG-DSPE, and F-PEG-Chol in SMEDDS on the absorption of curcumin in colon mucosa was studied with a colon perfusing experiment in rats. The results showed the absorption percentage of SMEDDS containing F-PEG-CHEMS in rat colons was better than that containing F-PEG-DSPE or F-PEG-Chol at the same concentration, and CUR-FSMEDDS with the weight ratio of F-PEG-CHEMS to Cremophor EL at 1:100 was higher compared with when the ratio was at 0.5:100 or $3: 100$. In addition, cytotoxicity and cellular uptake studies indicated that due to folate-mediated endocytosis, FSMEDDS showed a higher ability to actively target tumor cells with overexpressed folate receptors on the cell surface in comparison with SMEDDS. In addition, the in vitro release of CUR-FSMEDDS in colon-targeted capsules showed this formulation of curcumin can reach the colon efficiently and release the drug immediately. It could be concluded that FSMEDDS-filled colon-targeted capsules are a potential carrier for colon delivery of curcumin.

\section{Acknowledgments}

This work is supported by the National Natural Science Foundation of China (No 30973646).

\section{Disclosure}

The authors report no conflicts of interest in this work.

\section{References}

1. Basile V, Ferrari E, Lazzari S, Belluti S, Pignedoli F, Imbriano C. Curcumin derivatives: molecular basis of their anti-cancer activity. Biochem Pharmacol. 2009;78(10):1305-1315.

2. Goel A, Kunnumakkara AB, Aggarwal BB. Curcumin as "Curecumin": from kitchen to clinic. Biochem Pharmacol. 2008;75(4):787-809.

3. Johnson JJ, Mukhtar H. Curcumin for chemoprevention of colon cancer. Cancer Lett. 2007;255(2):170-181.

4. Sharma RA, Gescher AJ, Steward WP. Curcumin: the story so far. Eur J Cancer. 2005;41(13):1995-1968.

5. Prajakta D, Ratnesh J, Chandan K, et al. Curcumin loaded $\mathrm{pH}$-sensitive nanoparticles for the treatment of colon cancer. J Biomed Nanotechnol. 2009;5(5):445-455.

6. Hong JY, Kim JK, Song YK, Park JS, Kim CK. A new self-emulsifying formulation of itraconazole with improved dissolution and oral absorption. J Control Release. 2006;110(2):332-338.

7. Zhang P, Liu Y, Feng N, Xu J. Preparation and evaluation of selfmicroemulsifying drug delivery system of oridonin. Int J Pharm. 2008;355(1-2):269-276.

8. Balakrishnan P, Lee BJ, Oh DH, et al. Enhanced oral bioavailability of dexibuprofen by a novel solid self-emulsifying drug delivery system (SEDDS). Eur J Pharm Biopharm. 2009;72(3):539-545.

9. Zhao Y, Wang C, Chow AH, et al. Self-nanoemulsifying drug delivery system (SNEDDS) for oral delivery of Zedoary essential oil: formulation and bioavailability studies. Int J Pharm. 2010;383(1-2):170-177.

10. Shia J, Klimstra DS, Nitzkorski JR, et al. Immunohistochemical expression of folate receptor alpha in colorectal carcinoma: patterns and biological significance. Hum Pathol. 2008;39(4):498-505.

11. Kim SH, Kim JK, Lim SJ, Park JS, Lee MK, Kim CK. Folate-tethered emulsion for the target delivery of retinoids to cancer cells. Eur J Pharm Biopharm. 2008;68(3):618-625.

12. Xiong S, Yu B, Wu J, Li H, Lee RJ. Preparation, therapeutic efficacy and intratumoral localization of targeted daunorubicin liposomes conjugating folate-PEG-CHEMS. Biomed Pharmacother. 2011;65(1):2-8.

13. Lee RJ, Low PS. Folate-mediated tumor cell targeting of liposomeentrapped doxorubicin in vitro. Biochim Biophys Acta. 1995;1233(2): 134-144. 
14. Craig DQM, Barker SA, Banning D, Booth SW. An investigation into the mechanisms of self-emulsification using particle size analysis and low frequency dielectric spectroscopy. Int J Pharm. 1995;114(1): 103-110.

15. Subramanian N, Ray S, Ghosal SK, Bhadra R, Moulik SP. Formulation design of self-microemulsifying drug delivery systems for improved oral bioavailability of celecoxib. Biol Pharm Bull. 2004;27(12): 1993-1999.

16. Rispoli F, Shah V. A new efficient mixture screening design for optimization of media. Biotechnol Prog. 2009;25(4):980-985.

17. Han X, Liu J, Liu M, et al. 9-NC-loaded folate-conjugated polymer micelles as tumor targeted drug delivery system: preparation and evaluation in vitro. Int J Pharm. 2009;372(1-2):125-131.

18. Xiang G, Wu J, Lu Y, Liu Z, Lee RJ. Synthesis and evaluation of a novel ligand for folate-mediated targeting liposomes. Int J Pharm. 2008;356(1-2):29-36.

19. Zhang N, Ping Q, Huang G, Xu W, Cheng Y, Han X. Lectin-modified solid lipid nanoparticles as carriers for oral administration of insulin. Int J Pharm. 2006;327(1-2):153-159.

20. Xia CQ, Shen WC. Tyrphostin-8 enhances transferrin receptor-mediated transcytosis in Caco-2-cells and increases hypoglycemic effect of orally administered insulin-transferrin conjugate in diabetic rats. Pharm Res. 2001;18(2):191-195.

21. Yin Y, Chen D, Qiao M, Lu Z, Hu H. Preparation and evaluation of lectin-conjugated PLGA nanoparticles for oral delivery of thymopentin. J Control Release. 2006;116(3):337-345.

22. Liu Y, Chen ZQ, Zhang X, et al. An improved formulation screening and optimization method applied to the development of a self-microemulsifying drug delivery system. Chem Pharm Bull (Tokyo). 2010;58(1):16-22.

23. Yao J, Lu Y, Zhou JP. Preparation of nobiletin in self-microemulsifying systems and its intestinal permeability in rats. J Pharm Pharm Sci. 2008;11(3):22-29.

24. Nekkanti V, Karatgi P, Prabhu R, Pillai R. Solid self-microemulsifying formulation for candesartan cilexetil. AAPS Pharm Sci Tech. 2010;11(1):9-17.

25. Hu K, Li J, Shen Y, et al. Lactoferrin-conjugated PEG-PLA nanoparticles with improved brain delivery: in vitro and in vivo evaluations. J Control Release. 2009;134(1):55-61.
26. Setthacheewakul S, Mahattanadul S, Phadoongsombut N, Pichayakorn W, Wiwattanapatapee R. Development and evaluation of self-microemulsifying liquid and pellet formulations of curcumin, and absorption studies in rats. Eur J Pharm Biopharm. 2010;76(3): 475-485.

27. Gao Y, Wang Y, Ma Y, et al. Formulation optimization and in situ absorption in rat intestinal tract of quercetin-loaded microemulsion. Colloids Surf B Biointerfaces. 2009;71(2):306-314.

28. Pradhan P, Giri J, Rieken F, et al. Targeted temperature sensitive magnetic liposomes for thermo-chemotherapy. J Control Release. 2010;142(1):108-121.

29. Lin JJ, Chen JS, Huang SJ, et al. Folic acid-Pluronic F127 magnetic nanoparticle clusters for combined targeting, diagnosis, and therapy applications. Biomaterials. 2009;30(28):5114-5124.

30. Zhao XB, Muthusamy N, Byrd JC, Lee RJ. Cholesterol as a bilayer anchor for PEGylation and targeting ligand in folate-receptor-targeted liposomes. J Pharm Sci. 2007;96(9):2424-2435.

31. Yu HL, Huang QR. Enhanced in vitro anti-cancer activity of curcumin encapsulated in hydrophobically modified starch. Food Chem. 2010;119(2):669-674.

32. Kaminaga Y, Nagatsu A, Akiyama T, et al. Production of unnatural glucosides of curcumin with drastically enhanced water solubility by cell suspension cultures of Catharanthus roseus. FEBS Lett. 2003;555(2):311-316.

33. Tønnesen HH, Másson M, Loftsson T. Studies of curcumin and curcuminoids. XXVII. Cyclodextrin complexation: solubility, chemical and photochemical stability. Int J Pharm. 2002;244(1-2):127-135.

34. $\mathrm{Xu} \mathrm{Y}$, Jin $\mathrm{X}$, Ping Q, et al. A novel lipoprotein-mimic nanocarrier composed of the modified protein and lipid for tumor cell targeting delivery. J Control Release. 2010;146(3):299-308.

35. Mulik RS, Mönkkönen J, Juvonen RO, Mahadik KR, Paradkar AR. Transferrin mediated solid lipid nanoparticles containing curcumin: enhanced in vitro anticancer activity by induction of apoptosis. Int $J$ Pharm. 2010;398(1-2):190-203.
International Journal of Nanomedicine

\section{Publish your work in this journal}

The International Journal of Nanomedicine is an international, peerreviewed journal focusing on the application of nanotechnology in diagnostics, therapeutics, and drug delivery systems throughout the biomedical field. This journal is indexed on PubMed Central, MedLine, CAS, SciSearch $\AA$, Current Contents ${ }^{\circledR} /$ Clinical Medicine,

\section{Dovepress}

Journal Citation Reports/Science Edition, EMBase, Scopus and the Elsevier Bibliographic databases. The manuscript management system is completely online and includes a very quick and fair peer-review system, which is all easy to use. Visit http://www.dovepress.com/ testimonials.php to read real quotes from published authors. 